\title{
Can the Double-Pillar Regulation Drive Enterprise Innovation?
}

\author{
Bing Ma (iD) \\ Economics and Management School, Wuhan University, Wuhan 430072, China \\ Correspondence should be addressed to Bing Ma; bingma@whu.edu.cn \\ Received 27 January 2022; Accepted 15 February 2022; Published 8 March 2022 \\ Academic Editor: Miaochao Chen \\ Copyright (c) 2022 Bing Ma. This is an open access article distributed under the Creative Commons Attribution License, which \\ permits unrestricted use, distribution, and reproduction in any medium, provided the original work is properly cited. \\ This paper explores the effect of the Double-pillar regulation on promoting enterprise innovation and its influencing mechanism. \\ Based on the panel data of A-share listed nonfinancial enterprises in China from 2010 to 2019, this paper empirically examines the \\ driving effect of the Double-pillar regulation on enterprise innovation and its influencing mechanism. The empirical results \\ demonstrate that the Double-pillar regulation can promote enterprise innovation, and there is significant regional heterogeneity. \\ The Double-pillar regulation has a stronger driving effect on the innovation of state-owned enterprises. The Double-pillar \\ regulation can effectively reduce the financialization of enterprises, thus boosting enterprise innovation. The degree of financing \\ constraint and the improvement of enterprise risk-taking level will enhance the driving effect of the double-pillar regulation on \\ enterprise innovation. The research of this paper promotes the understanding of the effect, mechanism, and regional differences of \\ enterprise innovation under the Double-pillar regulation. Meanwhile, it also examines the necessity of building the Double-pillar \\ regulation framework.
}

\section{Introduction}

After the global financial crisis triggered by the US subprime mortgage crisis in 2008 , the attention of financial regulators has gradually shifted from a microprudential framework to a macroprudential framework. This crisis shows that maintaining the soundness of one or more financial institutions is not a sufficient condition to ensure financial stability. As a result, the old path that the central bank relies solely on monetary policy to ensure the stability of the financial system is unsustainable. After the crisis, countries around the world have been seeking macroprudential policy tools suitable for their own countries. The report of the 19th National Congress of the Communist Party of China mentions that the Double-pillar regulation framework of monetary policy and macroprudential policy should be strengthened, and the bottom line of systemic financial risks should be firmly safeguarded, fully demonstrating that the Double-pillar regulation policy is of vital significance for maintaining financial stability. The ultimate goal of financial stability is to make the economy develop better. Moreover, innovation is an essential catalyst of economic growth, and enterprises are an indispensable element of economic entities. The effect of enterprise innovation on economic growth should not be ignored.

Monetary policy can individually affect the financing activities of enterprises through risk-taking channels, credit channels, bank balance sheets, loan quality, capital flows, and other aspects, thus affecting the innovation activities of enterprises [1-6]. From the perspective of macroprudential policy, macroprudential policy can effectively reduce the procyclicality of bank credit expansion and lower the banks' risk-taking, thus affecting the financing activities and innovation activities of enterprises [7-10]. Both monetary policy and macroprudential policy can affect bank loans, credit flows, and other aspects, thus affecting enterprise innovation.

In the existing literature, there is relatively little research on Double-pillar regulation. Some scholars have theoretically analyzed the Double-pillar regulation framework and expounded the internal logic and the effect of the double-pillar regulation $[11,12]$. On this basis, some scholars have established the DSGE model to prove that the double-pillar regulation can effectively reduce systemic risks and economic leverage ratio and maintain macroeconomic stability [13-17]. Subsequently, a small 
number of scholars have empirically verified that the Double-pillar regulation can effectively reduce bank risks and achieve its microstability effect $[18,19]$. Based on the above review of the literature related to the Double-pillar, it is found that the existing research on the double-pillar mainly focuses on theoretical analysis and its stabilizing effect. Few literature explores through empirical research the effect of the double-pillar regulation on microsubjects, especially enterprises. In terms of the research results in enterprise innovation, the existing literature is mainly divided into the following aspects: the effect of the legal system on enterprise innovation activities [20,21], the effect of government subsidies and tax incentives on innovation investment of enterprises [22], and the effect of financial development and banking structure on enterprises' investment in innovation [23]. Through reviewing the literature on the Double-pillar and enterprise innovation, it is found that the effect of the Double-pillar regulation on enterprise innovation still needs to be further supplemented.

This paper aims to explore the following issues: (1) the effect of the Double-pillar regulation on enterprise innovation. (2) The mechanism of the Double-pillar regulation on enterprise innovation. Its theoretical value includes (1) Supplementing the literature on the effect of coordination and cooperation between the Double-pillar on enterprise innovation. (2) Empirically testing the effect of the Doublepillar regulation on enterprise innovation. (3) Exploring the mechanism of the Double-pillar regulation affecting enterprise innovation. Its practical significance lies in investigating whether the Double-pillar regulatory framework can effectively promote enterprise innovation and economic growth while maintaining financial stability.

\section{Theoretical Analysis and Research Hypotheses}

\subsection{The Effect of the Double-Pillar Regulation on Enterprise} Innovation. In 2016, the People's Bank of China first put forward the "Double-pillar regulation" framework, which means that the coordination of monetary policy and macroprudential policy can help to maintain the stability of the financial system. On the one hand, through the coordination between monetary policy tools and macroprudential policy tools, the Double-pillar regulation can effectively restrain systemic financial risks, thus constructing a stable environment for innovation activities, enhancing the risk tolerance of enterprises for innovation activities and driving enterprises to carry out innovation activities [24]. On the other hand, the Double-pillar regulation framework can effectively control the credit flow of banks, strengthen the monitoring of credit quality by banks, promote the capital flow to innovative projects with great development potential, and help enterprises innovate. In addition, the Double-pillar regulation can reduce the leverage ratio of enterprises, thus optimizing the financial allocation of enterprises and promoting the investment of enterprises in innovation activities
[25]. Based on this, this paper puts forward the following hypotheses.

$\mathrm{H} 1$ : the double-pillar regulation can effectively drive enterprise innovation.

Due to the different economic development and superstructure development, there are significant differences in the driving effect of the Double-pillar regulation on enterprise innovation. This paper holds that the Doublepillar regulation will have a more significant effect on enterprise innovation in the eastern region due to its relatively better economic development and superstructure development. Similarly, compared with the western region, the Double-pillar regulation will play a more significant role in driving enterprise innovation in the central region. Moreover, compared with non-state-owned enterprises, stateowned enterprises can be more responsive to policy implementation than non-state-owned enterprises because of their nature. In addition, owing to the "invisible guarantor," the government, state-owned enterprises have more access to bank credit and preferential credit policies. Therefore, the Double-pillar regulation has a more significant, driving effect on the innovation of state-owned enterprises. In this context, this paper puts forward the following hypotheses.

$\mathrm{H} 2$ : there are regional differences in the driving effect of the Double-pillar regulation on enterprise innovation, and the driving effect is the most significant in the eastern region.

H3: compared with non-state-owned enterprises, the Double-pillar regulation has a stronger driving effect on the innovation of state-owned enterprises.

\subsection{The Effect Mechanism of the Double-Pillar Regulation on} Enterprise Innovation. The innovation activities of enterprises are characterized by long periodicity, huge investment amount, and uncertain return on investment, which makes the innovation activities of enterprises face higher costs and financing constraints, and reduces the enterprises' willingness to invest in innovation $[26,27]$. Hence, enterprises will allocate more financial assets with high liquidity, thus promoting the financialization of enterprises. The main reasons for this phenomenon are enterprises' capital arbitrage motivation and capital reserve motivation. Financialization of enterprises simply means that the proportion of investment in financial assets is too high. Based on the market arbitrage motivation, the excessive allocation of financial assets by enterprises will reduce the enterprises' willingness to innovate and then cut down the funds for innovation activities. In addition, excessive financialization of enterprises will cause bubbles in their assets, leading them to pay more attention to short-term interests and reducing investment in innovation. Under the double-pillar regulatory framework, financial supervision departments will strengthen the supervision of shadow banking, lower enterprises' allocation of financial assets, and avoid the 
emergence of financialization, thus increasing their willingness to innovate [28].

H4: the double-pillar regulation can effectively reduce the financialization of enterprises and promote enterprise innovation.

Myers puts forward the pecking order theory in 1984 and argues that the external financing cost of enterprise investment is higher than internal financing due to information asymmetry and other factors so that enterprise investment will be restricted by financing factors, resulting in financing constraints. Moreover, financing constraints can seriously restrict the innovation activities of enterprises. Therefore, under the Double-pillar regulation framework, the higher the degree of financing constraint, the more obvious the driving effect of the Double-pillar regulation on enterprise innovation [29].

H5: the driving effect of the double-pillar regulation on enterprise innovation will vary with different degrees of financing constraint. The higher the degree of financing constraint, the stronger the driving effect of the Double-pillar regulation on enterprise innovation.

Enterprise risk-taking represents the degree of their acceptance of risk, and enterprise innovation means that enterprises need to take risks. In this regard, the higher the tolerance of enterprises to risks, the stronger their innovation will be and the more they will invest in innovation. Therefore, the level of enterprise risk-taking has a positive effect on the innovation activities of enterprises. The higher level of enterprise risk-taking, the more enterprises can bear the failure of innovation, which is conducive to promoting enterprise innovation. This paper holds that under the Double-pillar regulation framework, the higher the level of risk-taking, the stronger the driving effect of the Doublepillar regulation on innovation.

H6: the driving effect of the Double-pillar regulation on enterprise innovation will vary with the level of enterprise risk-taking. The higher level of enterprise risktaking, the stronger the driving effect of the Doublepillar regulation on enterprise innovation.

\section{Research Design}

\subsection{Model Setting}

3.1.1. Baseline Model Setting. This paper adopts the panel fixed effect model to examine the impact of the Double-pillar regulation on enterprise innovation, as follows:

$$
\begin{aligned}
\mathrm{RD}_{i t}= & \alpha_{1}+\alpha_{2} \mathrm{MP}_{i t}+\alpha_{3} \mathrm{MPI}_{i t}+\alpha_{4} \mathrm{MMPI}_{i t} \\
& +\alpha_{5} \text { Control }_{i t}+\mu_{i}+\gamma_{j}+\varepsilon_{i, t} .
\end{aligned}
$$

In this model, $i$ represents an enterprise; $t$ represents the year; RD represents enterprise innovation; MP represents monetary policy; MPI represents macroprudential policy; MMPI represents the double-pillar regulation; Control represents a series of control variables; $\mu_{i}$ represents the fixed effect of the industry where the enterprise $i$ belongs; $\gamma_{j}$ represents the fixed effect of the region where the enterprise $i$ locates. It is worth noting that this paper focuses on $\alpha_{4}$. If $\alpha_{4}$ is significantly greater than 0 , it means that the double-pillar regulation can effectively drive enterprise innovation.

3.1.2. Mediating Effect Model. To test whether financialization of enterprises acts as an intermediary in the effect of the double-pillar regulation on enterprise innovation, this paper refers to Zhonglin Wen's mediating effect test model, and the specific model is as follows:

$$
\begin{aligned}
\mathrm{RD}_{i t}= & \alpha_{1}+\alpha_{2} \mathrm{MP}_{i t}+\alpha_{3} \mathrm{MPI}_{i t}+\alpha_{4} \mathrm{MMPI}_{i t} \\
& +\alpha_{5} \text { Control }_{i t}+\mu_{i}+\gamma_{j}+\varepsilon_{i, t}, \\
\mathrm{fin}_{i t}= & \beta_{1}+\beta_{2} \mathrm{MP}_{i t}+\beta_{3} \mathrm{MPI}_{i t}+\beta_{4} \mathrm{MMPI}_{i t} \\
& +\beta_{5} \mathrm{Control}_{i t}+\mu_{i}+\gamma_{j}+\varepsilon_{i, t}, \\
\mathrm{RD}_{i t}= & \vartheta_{1}+\vartheta_{2} \mathrm{MP}_{i t}+\vartheta_{3} \mathrm{MPI}_{i t}+\vartheta_{4} \mathrm{MMPI}_{i t}+\vartheta_{5} \mathrm{fin}_{i t} \\
& +\vartheta_{6} \text { Control }_{i t}+\mu_{i}+\gamma_{j}+\varepsilon_{i, t} .
\end{aligned}
$$

Among them, fin represents the financialization of enterprises, and other variables are the same as those mentioned above. It needs to be emphasized here that this paper focuses on $\alpha_{4}$ in model (2), $\beta_{4}$ in model (3), and $\vartheta_{4}$ and $\vartheta_{5}$ in model (4). When $\alpha_{4} \beta_{4}$, and $\vartheta_{5}$ are significant, it means that the financialization of enterprises acts as an intermediary in the effect of the double-pillar regulation on enterprise innovation. On this basis, if $\vartheta_{4}$ is significant, it is a partial intermediary. If it is significant, it is a complete intermediary.

3.1.3. Moderating Effect Model. To test Hypothesis 5 and Hypothesis 6, the interaction terms of financing constraint and monetary policy, financing constraint and macroprudential policy, and financing constraint and the doublepillar regulation are included in the baseline model to test the moderating effect of financing constraint. Similarly, the product terms of enterprise risk-taking and monetary policy, macroprudential policy, and the double-pillar regulation are included in the baseline model to test the moderating effect of enterprise risk-taking. The specific model is shown as follows:

$$
\begin{aligned}
\mathrm{RD}_{i t}= & \alpha_{1}+\alpha_{2} \mathrm{MP}_{i t}+\alpha_{3} \mathrm{MPI}_{i t}+\alpha_{4} \mathrm{MMPI}_{i t}+\alpha_{4} \mathrm{MP}_{i t} * \mathrm{KZ}_{i t} \\
& +\alpha_{5} \mathrm{MPI}_{i t} * \mathrm{KZ}_{i t}+\alpha_{6} \mathrm{MMPI}_{i t} * \mathrm{KZ}_{i t}+\alpha_{7} * \mathrm{Control}_{i t} \\
& +\mu_{i}+\gamma_{j}+\varepsilon_{i, t}, \\
\mathrm{RD}_{i t}= & \beta_{1}+\beta_{2} \mathrm{MP}_{i t}+\beta_{3} \mathrm{MPI}_{i t}+\beta_{4} \mathrm{MMPI}_{i t}+\beta_{4} \mathrm{MP}_{i t} \\
& * \operatorname{RiskT}_{i t}+\beta_{5} \mathrm{MPI}_{i t} * \mathrm{RiskT}_{i t}+\beta_{6} \mathrm{MMPI}_{i t} \\
& * \operatorname{RiskT}_{i t}+\beta_{7} * \mathrm{Control}_{i t}+\mu_{i}+\gamma_{j}+\varepsilon_{i, t} .
\end{aligned}
$$

Among them, KZ means the degree of financing constraint. RiskT represents the level of enterprise risk-taking. The descriptions of other variables are the same as those mentioned above. This paper focuses on $\alpha_{6}$ and $\beta_{7}$. If $\alpha_{6}$ and $\beta_{7}$ are significantly greater than 0 , it means that the 
higher the degree of financing constraint, the more significant the driving effect of the double-pillar regulation on enterprise innovation; The higher level of enterprise risktaking, the more significant the driving effect of the doublepillar regulation on enterprise innovation.

\subsection{Description of Variables and Data}

3.2.1. Enterprise Innovation (RD). For enterprise innovation, this paper takes enterprise's R\&D expenditure as the proxy indicator of enterprise's investment in innovation according to the common practice in most literature. In addition, this paper adopts common methods to carry out the logarithmic processing for enterprise's R\&D expenditure to reduce the heteroscedasticity between models.

3.2.2. Proxy Variable of Monetary Policy (MP). This paper follows the practice of most literature, taking $M 2$ growth rate and one-week Shibor as proxy indicators of monetary policy. M2 supply is the main proxy variable, and Shibor is used for the robustness test.

3.2.3. Proxy Variable of Macroprudential Policy (MPI). Based on the existing literature, the quantification of macroprudential policies can be divided into two categories: one is to use one or more macroprudential policy tools as proxy variables. For example, Ke Song [30] uses loan-tovalue ratio (LTV) and deposit reserve ratio as a quantitative indicator of macroprudential policy. The other is to build the indicator of macroprudential policy according to the implementation effect of macroprudential policy tools and take this indicator as a proxy variable. This paper holds that the second method is more comprehensive in measuring macroprudential policy, so this paper chooses the second indicator. Moreover, this paper mainly refers to the IMFbased database of Jicheng Huang to build MPI [19].

3.2.4. Double-Pillar Regulation (MMPI). This paper refers to the practices of Jiecheng Huang, Junjie Zhou, etc., and measures the effect of the double-pillar regulation with the interaction term of monetary policy variable and macroprudential policy variable $[18,19]$.

3.2.5. Financialization of Enterprises ( $\mathrm{fin}$ ). This paper refers to the practice of Jun Song and measures the ratio of year-end nonmonetary financial assets to total year-end assets, namely (trading financial assets + derivative financial assets + net held-to-maturity investment + net loans and advances + net investment real estate + net available-for-sale financial assets + dividends receivable + accrued interest)/total assets.

3.2.6. Financing Constraint (KZ). Referring to the existing literature, this paper selects the $\mathrm{KZ}$ index as the proxy indicator of financing constraint. The larger the $\mathrm{KZ}$ index, the higher the degree of financing constraint.
3.2.7. Enterprise's Risk-Taking (RiskT). This paper refers to the practice of Minggui $\mathrm{Yu}$ and uses the volatility of enterprise profits to measure. The specific practice is as follows:

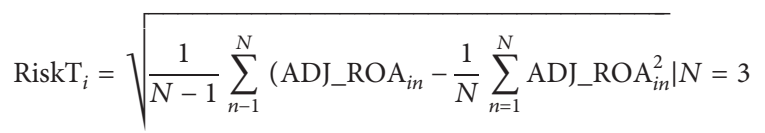

ADJ_ROA $_{i n}=\frac{\text { EBITDA }_{i n}}{\operatorname{ASSETS}_{i n}}-\frac{1}{X} \sum_{k=1}^{X} \frac{\operatorname{EBITDA}_{k n}}{\operatorname{ASSETS}_{k n}}$.

Among them, $i$ represents the enterprise, and $n$ represents the period in the observation period, with values of 1,2 , 3; $X$ represents the total number of enterprises in an industry, and $k$ represents the $k^{\text {th }}$ enterprise in the industry. RiskT represents the level of enterprise risk-taking. The larger the value, the higher level of enterprise risk-taking. EBITDA represents earnings before interest and tax, and ASSETS represents the total assets.

3.2.8. Control Variables (Control). This paper mainly selects the asset-liability ratio (lev), total assets turnover rate (tat), the net return on total assets rate (rot), industry Tobin $Q$ value $(Q)$, enterprise Tobin q value $(q)$, technical level $(\mathrm{tl})$, enterprise size (size), director number $(\mathrm{dn})$, and independent director size (id) as shown in Table 1.

3.3. Data Sources and Descriptive Statistical Analysis. This paper selects the listed companies in stock markets of Shanghai and Shenzhen in China from 2010 to 2019 as the samples of enterprise. From Table 2, since the double-pillar regulatory framework came to the stage gradually after the financial crisis in 2008, this paper takes samples from 2010 considering that it would take some time to perfect the double-pillar regulatory framework. In the data processing stage, firstly, financial enterprises are excluded due to their special characteristics and the large difference between their R\&D investment and other industries. Secondly, because there are big problems in the operation of ST and $*$ ST enterprises, their data cannot be used, so these enterprises are excluded. Finally, the data with serious missing $\mathrm{R} \& \mathrm{D}$ investment and enterprise characteristic variables are excluded, and the missing data are supplemented by interpolation methods and other methods. Therefore, nearly 20,853 samples are obtained. To prevent the extreme values in the sample data from causing errors in the results, this research carries out the two-sided 1\% winsorization of the continuous variables. The above-mentioned enterprise variable data, M2 supply, and $\mathrm{KZ}$ index all come from the CSMAR database. One-week Shibor data comes from the official website of Shibor, and the relevant data used to construct macroprudential index MPI comes from the official websites of IMF, People's Bank of China, and CBRC.

\section{Empirical Analysis}

4.1. Regression Results of the Baseline Model. Table 3 presents the regression results of the baseline model. From Table 3, it can be seen that the regression coefficients of MMPI in Columns (1), 
(2), (3), and (4) are all significantly greater than 0 . This means the double-pillar regulation is positively correlated with enterprise innovation, indicating that it can effectively drive enterprise innovation, so Hypothesis 1 is verified. Moreover, the regression coefficient of monetary policy is significantly positive and the regression coefficient of macroprudential policy is significantly negative. This indicates that loose monetary policy is helpful for enterprises to carry out innovation activities, while tight macroprudential policy will inhibit enterprises from carrying out innovation. The possible reason is that loose monetary policy can prompt banks to lower the loan threshold and enable enterprises to obtain more external funds, thus increasing their investment in innovation. However, the tight macroprudential policy will increase banks' control over risks, thus leading banks to reduce their investment in high-risk innovative projects. Under the double-pillar regulatory framework, the coordination of monetary policy and macroprudential policy can effectively reduce the innovation risk of enterprises and promote their innovation activities.

4.2. Heterogeneity Test. Due to the distinctive conditions of economic development and superstructure development, the driving effect of the double-pillar regulation on enterprise innovation is also significantly different. Therefore, according to the places where enterprises are registered, this paper divides the samples into three groups of the eastern region, central region, and eastern region and then carries out regression, respectively. In addition, due to the "invisible guarantor," the government state-owned enterprises can enjoy more bank credit and credit preferential policies. There may be significant differences in the driving effect of the double-pillar regulation on enterprise innovation. This paper employs the dummy variable method. To be more specific, firstly, the dummy variable is set as Nature, stateowned enterprises as 0 , and non-state-owned enterprises as 1. Secondly, the interactive terms between the dummy variable and monetary policy, the dummy variable and macroprudential policy, and the dummy variable and the double-pillar regulation are included in the baseline model, respectively. If the regression coefficient between Nature and the double-pillar regulation is significantly positive, it indicates that the double-pillar regulation has a more obvious driving effect on innovation of non-state-owned enterprises; otherwise, it has a more significant driving effect on the innovation of state-owned enterprises.

Table 4 presents the heterogeneity test of the effect of the double-pillar regulation on enterprise innovation. Columns (1), (2), and (3) present the regression results of eastern, central, and western regions, showing that the regression coefficients of double-pillar regulation are significantly positive in eastern and central regions. This suggests that the double-pillar regulation drives enterprise innovation in both eastern and central regions. However, the regression results of the double-pillar regulation in the western region are not significant, which indicates that the double-pillar regulation has no obvious driving effect on enterprise innovation in the western region. The regression coefficients of the double-pillar regulation are the most significant in the eastern region, followed by the central region, and then the western region, which indicates that there are regional differences in the driving effect of the double-pillar regulation on enterprise innovation. The driving effect is the largest in the eastern region, followed by the central region, and then the western region, thus verifying Hypothesis 2. Column 4 shows that the coefficient of MMPI * Nature is significantly negative, indicating that the double-pillar regulation has less driving effect on the innovation of non-state-owned enterprises than stateowned enterprises. In other words, the driving effect of the double-pillar regulation on enterprise innovation is different due to the nature of enterprises, and it is more significant for the innovation of state-owned enterprises, thereby verifying Hypothesis 3 .

4.3. Mechanism Test. Based on the analysis mentioned above, it can be seen that the double-pillar regulation can effectively restrain the financialization of enterprises and then improve their willingness to innovate. This paper constructs a mediating effect model to empirically test whether this mechanism is established. In addition, since enterprise innovation will be influenced by financing constraints and enterprise risk-taking willingness, this paper also establishes a moderating effect model to explore whether financing constraint and enterprise risk-taking willingness play a moderating role in the process of the double-pillar regulation driving enterprise innovation.

Table 5 demonstrates the results of the mechanism test. Columns (1), (2), and (3) display the results of the mediating effect test. Columns (4) and (5) show the results of the moderating effect test. Column (1) indicates that MMPI is significantly positive, suggesting that the doublepillar regulation significantly promotes enterprise innovation. Column (2) shows that MMPI is significantly negative, indicating that the double-pillar regulation can effectively restrain the financialization of enterprises. Column (3) shows that fin is significantly negative, indicating that financialization of enterprises will inhibit enterprise innovation. Combining the regression results of Column (1) and (2), it can be concluded that the financialization of enterprises acts as an intermediary in the double-pillar regulation driving enterprise innovation. Meanwhile, MMPI in Column (3) is significantly positive, indicating that the financialization of enterprises acts as a partial intermediary. This means the double-pillar regulation can effectively reduce the financialization of enterprises and then drive enterprise innovation, so Hypothesis 4 is verified. It can be seen from Column (4) that the regression coefficient of $\mathrm{KZ} * \mathrm{MMPI}$ is significantly positive, indicating that the driving effect of the double-pillar regulation on enterprise innovation will increase as the degree of financing constraint increases. The higher the degree of financing constraint, the greater the driving effect of the double-pillar regulation on enterprise innovation. It can be seen from Column (5) that the regression coefficient of RiskT $*$ MMPI is significantly positive, suggesting that the higher level of enterprise risk- 
TABLE 1: Variable descriptions.

\begin{tabular}{|c|c|c|}
\hline Variable type & Variable name & Variant content \\
\hline Dependent variable & $\mathrm{RD}$ & The logarithmic representation of enterprise's $R \& D$ expenditure \\
\hline Explaining variable & $\begin{array}{l}\text { MP } \\
\text { MPI } \\
\text { MMPI }\end{array}$ & $\begin{array}{l}\text { M2 growth rate and one-week Shibor } \\
\text { Referring to the dummy variable construction method of Jicheng Huang } \\
\text { The product of monetary policy and macro-prudential policy }\end{array}$ \\
\hline Mediating variable & fin & Proxy variable for the financialization of enterprises \\
\hline Moderating variable & $\begin{array}{c}\mathrm{KZ} \\
\text { RiskT }\end{array}$ & $\begin{array}{c}\text { Proxy variable for financing constraint } \\
\text { Proxy variable for level of enterprise risk-taking }\end{array}$ \\
\hline Control variable & $\begin{array}{l}\text { lev } \\
\text { tat } \\
\text { rot } \\
Q \\
q \\
\text { tl } \\
\text { Size } \\
\text { dn } \\
\text { id }\end{array}$ & $\begin{array}{c}\text { Asset-liability ratio } \\
\text { Total assets turnover rate } \\
\text { Net return on total assets rate } \\
\text { Industry tobin } Q \\
\text { Enterprise tobin } q \text { value } \\
\text { Technical level, using fixed assets/total assets } \\
\text { Enterprise size, using the logarithmic representation of total assets } \\
\text { Director number } \\
\text { Independent director size, using independent director number/director number }\end{array}$ \\
\hline
\end{tabular}

TABle 2: Descriptive statistical analysis.

\begin{tabular}{|c|c|c|c|c|c|}
\hline Variable & Obs & Mean & Std. dev. & Min & Max \\
\hline $\mathrm{RD}$ & 20853 & 17.638 & 1.724 & 0 & 25.025 \\
\hline M2 & 20853 & 2.019 & 0.531 & 1 & 2.737 \\
\hline Shibor & 20853 & 2.973 & 0.561 & 2.139 & 4.084 \\
\hline mpi & 20853 & 7.059 & 4.926 & 0 & 16 \\
\hline $\mathrm{m} 2 \mathrm{mpi} 1$ & 20853 & 13.881 & 10.411 & 0 & 30.2 \\
\hline Shibormpi & 20853 & 20.202 & 12.942 & 0 & 40.266 \\
\hline fin & 20853 & 0.029 & 0.065 & 0 & 0.809 \\
\hline RiskT & 20853 & 0.027 & 0.037 & 0 & 0.475 \\
\hline $\mathrm{KZ}$ & 17967 & 0.257 & 2.277 & -10.906 & 10.849 \\
\hline lev & 20853 & 0.401 & 0.235 & 0 & 10.495 \\
\hline tat & 20853 & 0.637 & 0.488 & 0 & 11.416 \\
\hline rot & 20853 & 0.04 & 0.116 & -4.946 & 7.445 \\
\hline$Q$ & 20853 & 2.761 & 2.32 & 0 & 92.251 \\
\hline$q$ & 20853 & 1.871 & 0.774 & 0 & 10.726 \\
\hline tl & 20853 & 0.047 & 0.051 & 0 & 0.89 \\
\hline Size & 20853 & 22.019 & 1.327 & 0 & 28.636 \\
\hline dn & 20853 & 8.54 & 1.684 & 0 & 18 \\
\hline id & 20853 & 0.375 & 0.057 & 0 & 0.8 \\
\hline
\end{tabular}

TABLe 3: Regression results of the baseline model.

\begin{tabular}{|c|c|c|c|c|}
\hline & $(1)$ & $(2)$ & $(3)$ & $(4)$ \\
\hline MP & $\begin{array}{c}0.500080^{* * *} \\
(14.9011)\end{array}$ & $\begin{array}{c}0.285739^{* * *} \\
(9.5505)\end{array}$ & $\begin{array}{c}0.283886^{* * *} \\
(8.7828)\end{array}$ & $\begin{array}{c}0.276847^{* * *} \\
(8.4826)\end{array}$ \\
\hline MPI & $\begin{array}{c}-0.057048^{* * *} \\
(-7.3621)\end{array}$ & $\begin{array}{c}-0.051876^{* * *} \\
(-7.4817) \\
\end{array}$ & $\begin{array}{c}-0.036158^{* * *} \\
(-4.7561)\end{array}$ & $\begin{array}{c}-0.037564^{* * *} \\
(-5.1107)\end{array}$ \\
\hline MMPI & $\begin{array}{c}0.024279^{* * *} \\
(6.5375)\end{array}$ & $\begin{array}{c}0.020648^{* * *} \\
(6.2280)\end{array}$ & $\begin{array}{c}0.013597^{* * *} \\
(3.9362)\end{array}$ & $\begin{array}{c}0.014127^{* * *} \\
(4.2396)\end{array}$ \\
\hline Control & $\mathrm{N}$ & $\mathrm{Y}$ & $\mathrm{Y}$ & $\mathrm{Y}$ \\
\hline Fixed effect of the industry & $\mathrm{N}$ & $\mathrm{N}$ & $\mathrm{Y}$ & $\mathrm{Y}$ \\
\hline Fixed effect of the region & $\mathrm{N}$ & $\mathrm{N}$ & $\mathrm{N}$ & $\mathrm{Y}$ \\
\hline$N$ & 20853 & 20853 & 20852 & 20837 \\
\hline$R 2$ & 0.0460 & 0.2593 & 0.4504 & 0.5093 \\
\hline
\end{tabular}


TABLE 4: Heterogeneity test.

\begin{tabular}{|c|c|c|c|c|}
\hline & $\begin{array}{c}(1) \\
\text { Eastern region }\end{array}$ & $\begin{array}{l}(2) \\
\text { Central region } \\
\end{array}$ & $\begin{array}{c}(3) \\
\text { Western region }\end{array}$ & (4) \\
\hline MP & $\begin{array}{l}0.289699^{* * *} \\
\quad(7.4701)\end{array}$ & $\begin{array}{c}0.247279^{* * *} \\
(4.5110)\end{array}$ & $\begin{array}{l}0.194626^{* *} \\
(2.1672)\end{array}$ & $\begin{array}{c}0.267485^{* * *} \\
(6.0132)\end{array}$ \\
\hline MPI & $\begin{array}{c}-0.035715^{* * *} \\
(-4.1131)\end{array}$ & $\begin{array}{c}-0.037445^{* *} \\
(-2.2516)\end{array}$ & $\begin{array}{c}-0.050233^{* *} \\
(-2.2360)\end{array}$ & $\begin{array}{c}-0.064078^{* * *} \\
(-5.8896)\end{array}$ \\
\hline MMPI & $\begin{array}{c}0.013450^{* * *} \\
(3.4469)\end{array}$ & $\begin{array}{c}0.014831^{*} \\
(1.9361)\end{array}$ & $\begin{array}{c}0.016823 \\
(1.6150) \\
\end{array}$ & $\begin{array}{c}0.024741^{* * *} \\
(4.6873)\end{array}$ \\
\hline $\mathrm{MP} *$ nature & & & & $\begin{array}{c}0.014188 \\
(0.5968)\end{array}$ \\
\hline MPI $*$ nature & & & & $\begin{array}{c}0.041432^{* * *} \\
(3.7798)\end{array}$ \\
\hline MMPI $*$ nature & & & & $\begin{array}{c}-0.016669^{* * *} \\
(-3.0663) \\
\end{array}$ \\
\hline Control & $\mathrm{Y}$ & $\mathrm{Y}$ & $\mathrm{Y}$ & $\mathrm{Y}$ \\
\hline Fixed effect of the industry & $\mathrm{Y}$ & $\mathrm{Y}$ & $\mathrm{Y}$ & $\mathrm{Y}$ \\
\hline Fixed effect of the region & $\mathrm{Y}$ & $\mathrm{Y}$ & $\mathrm{Y}$ & $\mathrm{Y}$ \\
\hline$N$ & 15091 & 3691 & 2051 & 20837 \\
\hline$R 2$ & 0.4978 & 0.6103 & 0.5634 & 0.5102 \\
\hline
\end{tabular}

Table 5: Mechanism test.

\begin{tabular}{|c|c|c|c|c|c|}
\hline & $\begin{array}{l}(1) \\
\mathrm{RD} \\
\end{array}$ & $\begin{array}{l}\text { (2) } \\
\text { fin }\end{array}$ & $\begin{array}{l}(3) \\
\mathrm{RD} \\
\end{array}$ & $\begin{array}{l}(4) \\
\mathrm{RD}\end{array}$ & $\begin{array}{l}(5) \\
\mathrm{RD} \\
\end{array}$ \\
\hline MP & $\begin{array}{c}0.276847^{* * *} \\
(8.4826)\end{array}$ & $\begin{array}{c}0.026003^{* * *} \\
(17.3466)\end{array}$ & $\begin{array}{c}0.303210^{* * *} \\
(9.4345)\end{array}$ & $\begin{array}{c}0.286120^{* * *} \\
(8.7292)\end{array}$ & $\begin{array}{c}0.296968^{* * *} \\
(8.7032)\end{array}$ \\
\hline MPI & $\begin{array}{c}-0.037564^{* * *} \\
(-5.1107)\end{array}$ & $\begin{array}{c}0.001557^{* * *} \\
(6.0855)\end{array}$ & $\begin{array}{c}-0.035985^{* * *} \\
(-4.8858) \\
\end{array}$ & $\begin{array}{c}-0.034332^{* * *} \\
(-4.6373)\end{array}$ & $\begin{array}{c}-0.023573^{* * *} \\
(-2.6373)\end{array}$ \\
\hline MMPI & $\begin{array}{c}0.014127^{* * *} \\
(4.2396)\end{array}$ & $\begin{array}{c}-0.001087^{* * *} \\
(-7.5591)\end{array}$ & $\begin{array}{c}0.013025^{* * *} \\
(3.8853)\end{array}$ & $\begin{array}{c}0.012817^{* * *} \\
(3.8274)\end{array}$ & $\begin{array}{c}0.007580^{*} \\
(1.8799)\end{array}$ \\
\hline fin & & & $\begin{array}{c}-1.013870^{* * *} \\
(-5.5220)\end{array}$ & & \\
\hline $\mathrm{KZ} * \mathrm{MP}$ & & & & $\begin{array}{c}-0.015206^{* * *} \\
(-4.8474)\end{array}$ & \\
\hline $\mathrm{KZ} * \mathrm{MPI}$ & & & & $\begin{array}{c}-0.004823^{* *} \\
(-2.5411) \\
\end{array}$ & \\
\hline $\mathrm{KZ} * \mathrm{MMPI}$ & & & & $\begin{array}{c}0.002374^{* *} \\
(2.5626)\end{array}$ & \\
\hline $\operatorname{RiskT} *$ MP & & & & & $\begin{array}{c}-0.375037^{*} \\
(-1.6661)\end{array}$ \\
\hline RiskT $*$ MPI & & & & & $\begin{array}{c}-0.464876^{* *} \\
(-2.5056)\end{array}$ \\
\hline RiskT $*$ MMPI & & & & & $\begin{array}{c}0.211631^{* *} \\
(2.4669)\end{array}$ \\
\hline Control & $\mathrm{Y}$ & Y & $\mathrm{Y}$ & $\mathrm{Y}$ & $\mathrm{Y}$ \\
\hline Fixed effect of the industry & $\mathrm{Y}$ & $\mathrm{Y}$ & $\mathrm{Y}$ & $\mathrm{Y}$ & $\mathrm{Y}$ \\
\hline Fixed effect of the region & $\mathrm{Y}$ & $\mathrm{Y}$ & $\mathrm{Y}$ & $\mathrm{Y}$ & $\mathrm{Y}$ \\
\hline$N$ & 20837 & 20837 & 20837 & 20837 & 20837 \\
\hline$R 2$ & 0.5093 & 0.1550 & 0.5105 & 0.5111 & 0.5099 \\
\hline
\end{tabular}

taking, the stronger the driving effect of the double-pillar regulation on enterprise innovation. In other words, the driving effect of double-pillar regulation on enterprise innovation is more significant in enterprises with higher risk-taking levels. Therefore, Hypothesis 5 and Hypothesis 6 are verified.
4.4. Robustness Test. In this paper, the proxy variable of monetary policy is replaced by a one-week Shibor for baseline regression. In addition, the ratio of enterprise $\mathrm{R} \& \mathrm{D}$ investment to operating income (RD1) is also replaced. Then, the regression results are consistent with the results of baseline regression, indicating the model is robust as shown in Table 6. 
TABLE 6: Robustness test.

\begin{tabular}{|c|c|c|}
\hline & $\begin{array}{l}(1) \\
\mathrm{RD} \\
\end{array}$ & $\begin{array}{c}(2) \\
\text { RD1 }\end{array}$ \\
\hline One-week Shibor & $\begin{array}{c}-0.480285^{* * *} \\
(-8.7550)\end{array}$ & $\begin{array}{c}-1.136567^{* * *} \\
(-5.7700)\end{array}$ \\
\hline MPI & $\begin{array}{c}-0.122726^{* * *} \\
(-7.6918) \\
\end{array}$ & $\begin{array}{c}-0.301453^{* * *} \\
(-5.2762)\end{array}$ \\
\hline One-week ShiborMPI & $\begin{array}{c}0.038219^{* * *} \\
(6.6297)\end{array}$ & $\begin{array}{c}0.099118^{* * *} \\
(5.0260)\end{array}$ \\
\hline Control & $\mathrm{Y}$ & $\mathrm{Y}$ \\
\hline Fixed effect of the industry & $\mathrm{Y}$ & $\mathrm{Y}$ \\
\hline Fixed effect of the region & $\mathrm{Y}$ & $\mathrm{Y}$ \\
\hline$N$ & 20837 & 20837 \\
\hline$R 2$ & 0.5027 & 0.2990 \\
\hline
\end{tabular}

\section{Conclusions and Policy Implications}

This paper empirically tests the driving effect of the doublepillar regulation on enterprise innovation based on unbalanced panel data of A-share listed companies in China. Furthermore, it delves into the driving path of the doublepillar regulation on enterprise innovation. The main conclusions and policy implications are as follows.

Firstly, the double-pillar regulation can promote enterprise innovation, and there is significant regional heterogeneity. The double-pillar regulation has a more remarkable driving effect on the innovation of enterprises in the eastern region, followed by the central region. Meanwhile, it is not significant in the western region. In addition, the double-pillar regulation has a stronger driving effect on the innovation of state-owned enterprises. Therefore, this paper suggests further improving the double-pillar regulation framework, adjusting it according to local conditions, and implementing different levels of double-pillar regulation for enterprises with different ownership.

Secondly, the double-pillar regulation can effectively reduce the financialization of enterprises, thus promoting enterprise innovation. The financialization of enterprises acts as a partial intermediary in the process of the doublepillar regulation driving enterprise innovation. Therefore, this paper proposes that the supervision of shadow banking should be continuously strengthened in the double-pillar regulation to promote enterprise innovation.

Thirdly, the driving effect of the double-pillar regulation on enterprise innovation increases with the degree of financing constraint and level of enterprise risk-taking. Hence, this paper puts forward that monetary policy and macroprudential policy tools should be further innovated in the double-pillar regulation to ensure that they can effectively deal with changes in the financing constraint environment faced by enterprises and their own risk-taking willingness, thus reinforcing the driving effect of the doublepillar regulation on enterprise innovation.

\section{Data Availability}

The data used to support the findings of this study are available from the corresponding author upon request.

\section{Conflicts of Interest}

The authors declare that they have no conflicts of interest.

\section{Acknowledgments}

This study was supported by the National Social ScienceFund of China (Macroeconomic Impact of Liquidity Structure Imbalance and Monetary Policy Choice in China, Grant no. 14BJY187).

\section{References}

[1] C. Borio and H. Zhu, "Capital regulation, risk-taking and monetary policy: a missing link in the transmission mechanism?" Journal of Financial Stability, vol. 8, no. 4, 2012.

[2] Q. Zhang, Y. Qiao, and B. Zhang, "Does the bank risk-taking channel of China's monetary policy exist?" Journal of Financial Research, vol. 3, no. 08, pp. 84-97, 2013.

[3] W. Xu and B. Chen, "Bank credit and China's economic fluctuation: 1993-2005," Economics (Quarterly), vol. 8, no. 03, pp. 969-994, 2009.

[4] Y. Yao and H. Li, "An empirical study of transmission credit channels in China's monetary policy: new evidence of total financing structure," The Journal of World Economy, vol. 36, no. 03, pp. 3-32, 2013.

[5] Z. Huang, C. Qian, and X. Feng, "The effect of monetary and tax policies on enterprise R\&D investment," Securities Market Herald, vol. 10, no. 12, pp. 15-20, 2015.

[6] Q. Xie, "Monetary policy regulation, labor cost stickiness and enterprise innovation investment," Science and Technology Management Research, vol. 38, no. 19, pp. 47-53, 2018.

[7] C. H. Lim, A. Costa, F. Columba et al., "Macroprudential policy: what instruments and how to use them? Lessons from country experiences," IMF working papers, pp. 1-85, International Monetary Fund, Washington, D.C, USA, 2011.

[8] P. Kannan, P. Rabanal, and A. M. Scott, "Monetary and macroprudential policy rules in a model with house price booms," The B.E. Journal of Macroeconomics, vol. 12, no. 1, 2012.

[9] F. Valencia, "Monetary policy, bank leverage, and financial stability," Journal of Economic Dynamics and Control, vol. 47, pp. 20-38, 2014.

[10] M. Shao, "The impact of macro-prudential policies on the risk-taking of banks-Based on the perspective of cross-border 
empirical analysis," Journal of Financial Research, vol. 5, no. 05 , pp. 30-46, 2019.

[11] Y. Ma, "The theoretical and empirical basis of the "Doublepillar" regulatory framework," Journal of Financial Research, vol. 13, no. 12, pp. 18-37, 2019.

[12] J. Ma and X. He, "Coordination between monetary policy and macro-prudential policy," Journal of Financial Research, vol. 7, no. 12, pp. 58-69, 2019.

[13] Y Fang, Y. Wang, L. Huang, and W. Jia, "Research on the Double-pillar framework of macro-prudential and monetary policy-Based on the perspective of systemic risk," Journal of Financial Research, vol. 8, no. 12, pp. 106-124, 2019.

[14] Y. Ma and Y. Chen, "Coordination and collocation of macroprudential policies: simulation analysis based on China," Journal of Financial Research, vol. 12, no. 08, pp. 57-69, 2013.

[15] M. Hu, "Comparative study on deleveraging effect of monetary policy and Double-pillar regulatory framework," Statistics \& Information Forum, vol. 35, no. 11, pp. 57-67, 2020.

[16] D. Lu, Z. Zhou, and X. Zhou, "Research on the "Doublepillar" regulation and stability effect under the open economy," Journal of Financial Research, vol. 9, no. 12, pp. 125146, 2019.

[17] Y. Ma and L. Fu, “"Two pillars" regulation, policy coordination and macro-stability effect," Journal of Financial Research, vol. 12, no. 08, pp. 1-17, 2020.

[18] J. Zhou and X. Yi, "The effectiveness of the Double-pillar framework of "monetary policy plus macro-prudential policy"-An empirical study based on micro-data of commercial banks in China," Finance and Economics, vol. 4, no. 11, pp. 39-47, 2019.

[19] J. Huang, C. Yao, Y. Jiang, and T. Mou, "Study on the microstability effect of "two pillars" regulation," Journal of Financial Research, vol. 23, no. 07, pp. 1-20, 2020.

[20] Y. Chen and T. Puttitanun, "Intellectual property rights and innovation in developing countries," Journal of Development Economics, vol. 78, no. 2, pp. 474-493, 2005.

[21] M. Seitz and M. Watzinger, "Contract enforcement and R\&D investment," Research Policy, vol. 46, no. 1, pp. 182-195, 2017.

[22] B. Montmartin and M. Herrera, "Internal and external effects of R\&D subsidies and fiscal incentives: empirical evidence using spatial dynamic panel models," Research Policy, vol. 44, no. 5, pp. 1065-1079, 2015.

[23] Z. Zuo, "Financial structure and the promotion of national innovation capability: influencing mechanism and empirical evidence," Journal of Financial Research, vol. 38, no. 06, pp. $48-58+79,2012$.

[24] S. Ruan, H. Cha, W. Li, and X. Chen, "Double-pillar regulation and systemic financial risk," Economic Issues, vol. 15, no. 11, pp. 33-40, 2020.

[25] J. Liu and F. Gao, "“Double-pillar" regulation, credit resource allocation and enterprise leverage ratio," Wuhan Finance, vol. 8, no. 06, pp. 12-21, 2021.

[26] X. Lu, Y. Zheng, and J. Li, "Research on the effect of financing constraint on enterprise R\&D investment-Empirical evidence from Chinese listed high-tech companies," Accounting Research, vol. 7, no. 05, pp. 51-58+96, 2013.

[27] X. Ju, D. Lu, and Y. Yu, "Financing constraint, working capital management and enterprise innovation sustainability," Economic Research, vol. 48, no. 01, pp. 4-16, 2013.

[28] J. Yan and B. Wu, "Research on the supervision effect of shadow banking under the Double-pillar regulatory framework [J]," Financial Regulation Research, vol. 12, no. 03, pp. 35-50, 2020.
[29] J. R. Brown, S. M. Fazzari, and B. C. Petersen, "Financing innovation and growth: cash flow, external equity, and the 1990s R\&D boom," The Journal of Finance, vol. 64, no. 1, pp. 151-185, 2009.

[30] K. Song and Z. Li, "Macro-prudential policy, leverage ratio and bank risk-taking," Financial Regulation Research, vol. 24, no. 10, pp. 1-19, 2019. 